\title{
Aplicações taxonômicas da anatomia foliar de espécies amazônicas de Oenocarpus Mart. (Arecaceae) ${ }^{1}$
}

\author{
Rolf Junior Ferreira Silva ${ }^{2,3}$ e Raimunda Conceição de Vilhena Potiguara ${ }^{2}$
}

Recebido em 28/08/2007. Aceito em 15/02/2008

\begin{abstract}
RESUMO - (Aplicações taxonômicas da anatomia foliar de espécies amazônicas de Oenocarpus Mart. (Arecaceae)). Neste trabalho, objetivou-se estudar a anatomia foliar de Oenocarpus bacaba Mart., O. distichus Mart., O. mapora H. Karst. e O. minor Mart., visando verificar se existem entre as espécies diferenças anatômicas qualitativas úteis a sua delimitação taxonômica. Observou-se que as pinas de todos os representantes são anfiestomáticas e apresentam tecido epidérmico heteromórfico revestido por cutícula lisa, sobre a qual há depósitos de cera epicuticular nas formas filamentosas de extremidade gancheiforme e em placas retangulares; possuem estômatos tetracíticos e tricomas tectores bifilamentosos. O mesofilo é dorsiventral com braquiesclereídes, estruturas secretoras de mucilagem e feixes vasculares colaterais secundários e terciários, para os secundários diagnosticou-se quatro tipos, sendo o tipo III, com três vasos metaxilemáticos, o único comum às espécies. Características como: estômatos ciclocíticos; número de estratos do tecido de expansão; formas da nervura central e margem das pinas, mostraram-se peculiares a determinados taxa. Para o axis foliar, constatou-se que a forma e organização celulares do tecido parenquimático, nas regiões central e mediana, difere entre as espécies. Elaborou-se uma chave de identificação anatômica para as espécies de Oenocarpus Mart. analisadas, demonstrando que há entre estas diferenças estruturais significativas a nível qualitativo.
\end{abstract}

Palavras-chave: anatomia taxonômica, Arecaceae, Oenocarpus Mart.

\begin{abstract}
Leaf anatomy applied to the taxonomy of Amazonian species of Oenocarpus Mart. (Arecaceae)). Our aim was to study the leaf anatomy of Oenocarpus bacaba Mart., O. distichus Mart., O. mapora H. Karst. and O. minor Mart. in order to verify if there are qualitative anatomical features useful in taxonomy. Common features of the four species' leaflets are amphistomatic lamina; heteromorphic epidermal tissue; smooth cuticle; epicuticular wax in the form of hooked filaments and rectangular plates; tetracytic stomata; non-glandular, two-filamented trichomes; dorsiventral mesophyll with brachysclereids, mucilage secretory structures, type III secondary, with three metaxylem vessels, and tertiary vascular bundles. However, cyclocytic stomata; number of expansion tissue layers; shape of midrib and edge were peculiar to some taxa. The middle and central regions of the leaf axis differ among Oenocarpus Mart. species in cell shape and organization of the parenchyma tissue. An anatomical key is given for the species of Oenocarpus Mart., showing that there are significant qualitative structural differences among these species.
\end{abstract}

Key words: taxonomic anatomy, Arecaceae, Oenocarpus Mart.

\section{Introdução}

A família Arecaceae, considerada uma das mais comuns entre as Liliopsidas, é a única incluída na ordem Arecales, apresentando distribuição predominantemente pantropical (Cronquist 1981; Dahlgren \& Clifford 1982). Possui cerca 1.500 espécies em 200 gêneros endêmicos pertencentes a seis subfamílias, sendo que nas Américas está representada por 550 espécies e 67 gêneros (Henderson et al. 1995). No Brasil, Souza \& Lorenzi (2005) consideram 40 gêneros e 200 espécies.

As palmeiras, denominação vernacular das Arecaceae, constituem um dos componentes mais característicos da paisagem amazônica (Kahn 1988).
Região esta que abriga aproximadamente $50 \%$ dos gêneros e 30\% das espécies de palmeiras Neotropicas (Henderson et al. 1995). Kahn \& De Granville (1992) assinalam que das seis subfamílias definidas por Dransfield \& Uhl (1986) para as Arecaceae, cinco possuem representantes na Amazônia: Coryphoideae, Calamoideae, Ceroxyloideae, Arecoideae e Phytelephantoideae. Destas, Arecoideae é a que apresenta o maior número de gêneros à região (28 gêneros), sendo Astrocaryum G.F.W. Meyer, Bactris N.J. Jacquin ex Scopoli, Geonoma Willdenow e Oenocarpus Martius os mais diversificados, que juntos correspondem a mais de $50 \%$ do total de espécies. Para Oenocarpus Martius, Balick (1986) cita nove espécies

\footnotetext{
1 Parte da Dissertação de Mestrado do primeiro Autor

2 Museu Paraense Emílio Goeldi, Coordenação de Botânica, C. Postal 399, 66040-170 Belém, PA, Brasil

3 Autor para correspondência: rolfjr@hotmail.com
} 
que estão distribuídas no norte da América do Sul, extendendo-se ao norte para a América Central e, ao sul, para o Brasil e Bolívia.

No entanto, apesar da importância entre as plantas amazônicas, as palmeiras estão entre os grupos menos estudados na região, devido às dificuldades de coleta e a necessidade de grandes espaços para acondicioná-las, o que pode ser constatado pela pequena quantidade de exemplares depositados nos herbários (Kahn \& De Granville 1992; Miranda 2003).

Sabe-se que a anatomia vegetal fornece importantes contribuições à elucidação de relações ecológicas, taxonômicas e filogenéticas das plantas vasculares, assim como para a fisiologia das mesmas. Neste sentido, Uhl \& Dransfield (1987) enfatizam que estudos anatômicos são significativos para a classificação das palmeiras, visto que estas se mostram variáveis na estrutura interna tanto como na externa e, desta maneira, contribuem na determinação de novas características que permitem avaliar as suas inter-relações e mudanças evolutivas. Mesmo assim, trabalhos sobre Arecaceae na Amazônia têm direcionado-se principalmente aos aspectos alimentar, medicinal e sócio-econômico, conforme verificado em trabalhos etnobotânicos de Balick (1984), Jardim \& Cunha (1994), Jardim \& Stewart (1998), Rocha \& Silva (2005) e outros, havendo escassez de pesquisas histológicas com enfoque taxonômico.

Devido Oenocarpus Martius ser considerado um grupo uniforme do ponto de vista anatômico, no qual as diferenças estruturais quando presentes, dão-se apenas em nível quantitativo (Tomlinson 1961), somado ao alto grau de hibridação intra-específica, que o torna de difícil identificação, e por ser pouco estudado taxonomicamente, o presente trabalho objetivou estudar a anatomia foliar de quatro espécies deste gênero: $O$. bacaba Mart., O. distichus Mart., O. mapora H. Karst. e O. minor Mart., visando verificar se existem entre estas diferenças anatômicas qualitativas úteis a sua delimitação taxonômica.

\section{Material e métodos}

As espécies de Oenocarpus Mart. estudadas foram coletadas em duas áreas do município de Belém, Estado do Pará: no Parque Zoobotânico do Museu Paraense Emílio Goeldi (MPEG) e na Área de Proteção Ecológica do Guamá (APEG). Os espécimes encontram-se depositados no Herbário João Murça Pires (MG), pertencente ao MPEG, com as seguintes especificações: O. minor Mart. (MG 178490), O. distichus Mart. (MG 178491), O. mapora H. Karst. (MG 178492) e O. bacaba Mart. (MG 178493).
Para a análise anatômica, foram utilizadas folhas maduras retiradas da periferia da coroa, fixadas em F.A.A. ${ }_{70}$ (Johansen 1940) por 24 horas e, posteriormente, conservadas em álcool a 70\%. Foram consideradas três regiões ao axis foliar (ráquis, pecíolo e bainha foliar) e pinas: apical, mediana e basal (Fig. 1). Do axis foliar, foram retiradas amostras das regiões periférica, central e mediana (Fig. 2). Das pinas, foram selecionados o ápice, porção mediana e base do limbo, que foi subdividido em margem, nervura central e porção intermediária (Fig. 3). Nestas amostras, foram realizadas secções à mão livre, transversais e longitudinais, clarificadas em solução aquosa de hipoclorito de sódio comercial na proporção de 2:1 (v/v), com posterior lavagem em água destilada, coloração segundo Johansen (1940) e montagem em glicerina 50\% aquosa entre lâmina e
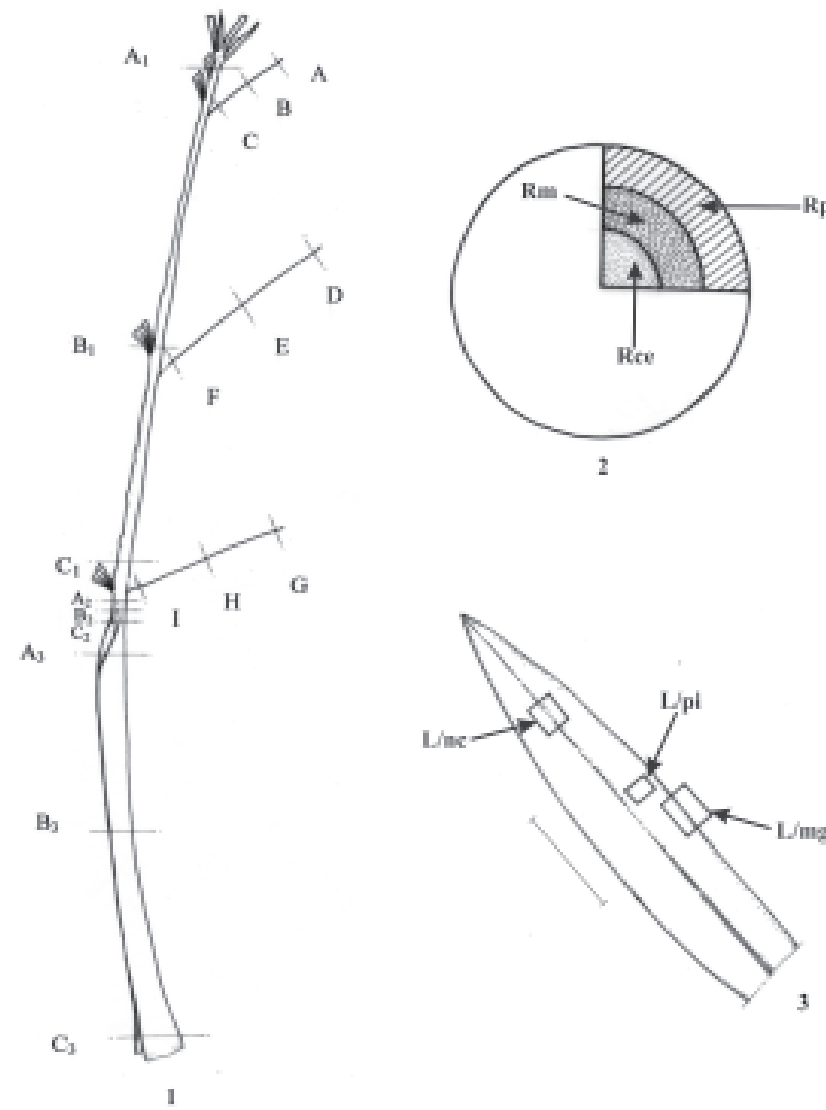

Figuras 1-3. Representação esquemática das secções realizadas nas folhas das espécies de Oenocarpus Mart. estudadas. 1. Representação geral. A: Ápice das pinas apicais; B: Porção mediana das pinas apicais; C: Base das pinas apicais; D: Ápice das pinas medianas; E: Porção mediana das pinas medianas; F: Base das pinas medianas; G: Ápice das pinas basais; H: Porção mediana das pinas basais; I: Base das pinas basais; A1: Ráquis apical; B1: Ráquis mediano; C1: Ráquis basal; A2: Pecíolo apical; B2: Pecíolo mediano; C2 : Pecíolo basal; A3: Bainha foliar apical; B3: Bainha foliar mediana; C3: Bainha foliar basal. 2. Axis foliar. Rce: Região central; Rm: Região mediana; Rp: Região periférica. 3. Pinas. L/mg: Limbo/margem; L/nc: Limbo/nervura central; L/pi: Limbo/porção intermediária. Barras: $1=1 \mathrm{~m} ; 3=15 \mathrm{~cm}$. 
lamínula. Quando necessário, amostras das regiões foliares acima citadas foram submetidas ao amolecimento de acordo com Carlquist (1982) e após desidratação, infiltração e inclusão em parafina histológica segundo Johansen (1940), foram seccionadas em micrótomo rotativo na espessura de $20 \mu \mathrm{m}$, coradas segundo o mesmo autor e montadas em bálsamo-do-canadá entre lâmina e lamínula.

Para o estudo da epiderme, secções das pinas foram fervidas em solução aquosa de ácido nítrico $20 \%$ por 30 minutos, seguindo-se a coloração, desidratação e pósdesidratação de Kraus \& Arduin (1997), com montagem em bálsamo-do-canadá entre lâmina e lamínula.

Testes histoquímicos foram empregados em material botânico não fixado, tanto em secções obtidas à mão como em epidermes dissociadas. A mucilagem foi detectada segundo Salatino \& Silva (1975), corpos silicosos e lignina foram diagnosticados segundo Jensen (1962).

Para o exame em microscopia eletrônica de varredura (MEV), amostras foliares desidratadas foram processadas em secador de ponto crítico, montadas em suportes metálicos e metalizadas com ouro com $20 \mathrm{~nm}$ de espessura por 150 segundos em corrente de $25 \mathrm{~mA}$.

Microanálises para substâncias minerais foram realizadas com detector de energy dispersive spectroscopy (EDS), equipado com janela Be e acoplado ao MEV.

As fotomicrografias e eletromicrografias foram obtidas, respectivamente, em fotomicroscopio Zeiss e microscópio eletrônico de varredura Leo modelo $1450 \mathrm{VP}$, sendo as escalas micrométricas projetadas nas mesmas condições ópticas.

A descrição dos dados anatômicos obtidos seguiu a terminologia adotada por Tomlinson $(1961 ; 1990)$, Metcalfe \& Chalk (1979) e Fahn (1990).

\section{Resultados e discussão}

Pinas - A epiderme em vista frontal, nas espécies de Oenocarpus Mart. estudadas, apresenta as regiões costal e intercostal da face adaxial formadas por células isodiamétricas de contornos hexagonais, com paredes anticlinais retas e organizadas paralelamente ao eixo longitudinal das pinas (Fig. 4), ocorrendo esporadicamente células de aspecto retangular e esférico (Fig. 5). $\mathrm{Na}$ região intercostal da face abaxial, as células epidérmicas são heterodimensionais de paredes anticlinais retas, apresentando formas variadas e sem organização definida, já na região costal estas células assumem aspectos retangulares, algumas com uma ou ambas as extremidades agudas e seguindo o sentido das nervuras (Fig. 6-7). Estômatos e tricomas ocorrem predominan- temente na face abaxial da epiderme (Fig. 6).

Os estômatos são tetracíticos, organizados em fileiras longitudinais paralelas ou perpendiculares às nervuras. Podem ocorrer células geminadas, isto é, células subsidiárias (polares ou não) comuns a dois estômatos (Fig. 7, 9). Tomlinson (1969) cita que estes tipos de estômatos são comuns a poucas famílias de Liliopsidas dentre elas as Arecaceae e Cyperaceae. Na superfície adaxial de $O$. minor Mart. e $O$. mapora H. Karst., foram observados também estômatos ciclocíticos isolados (Fig. 10).

Os tricomas, diagonalmente dispostos à superfície, são tectores, solitários, multicelulares e formados por filamento duplo envolto por cuticula lisa (Fig. 11). Apresentam região basal circundada por cinco a oito células epidérmicas de paredes ligeiramente onduladas, lignificadas, de aspecto semicircular e em disposição imbricada, posicionadas em nível superior as demais células da epiderme (Fig. 8, 12).

Dos cinco tipos de tricomas classificados por Tomlinson (1961) às palmeiras, o que mais se aproxima da descrição feita para os taxa de Oenocarpus Mart. corresponde ao tipo III, pois consisti de um filamento distal ou expansão semelhante a escudo. $\mathrm{O}$ autor considera, ainda, que tricomas estão em geral ausentes na epiderme foliar de Arecaceae, o que pode ser devido ao fato de ter trabalhado com material herborizado ou com estágios de desenvolvimento foliar em que tais apêndices estavam ausentes.

As faces superior e inferior das pinas encontram-se revestidas por cutícula lisa, sobre a qual ocorrem depósitos de cera epicuticular disposta em placas retangulares justapostas e em grupos filamentosos de extremidade gancheiforme (Fig. 13). A cera chega a obstruir o ostíolo de alguns estômatos (Fig. 14).

As pinas em secção transversal apresentam ambas as faces formadas por células epidérmicas de aspecto retangular com paredes anticlinais e periclinais espessadas, cobertas por cutícula lisa de espessamento conspícuo que se projeta ao nível das paredes anticlinais. As células epidérmicas são em geral isodiamétricas na face adaxial e heterodimensionais na abaxial. Na epiderme adaxial ocorre, esporadicamente, uma leve invaginação formando um sulco (Fig. 15-17). Estrutura semelhante foi descrita por Tomlinson (1961) na epiderme abaxial dos gêneros Ceroxylon Bonpl. ex DC e Pseudophoenix H. Wendl. ex Sarg., palmeiras pertencentes à subfamília Ceroxyloideae.

Corpos silicosos elípticos cobertos por pequenas granulações foram verificados no interior das epidermes adaxial e abaxial (Fig. 16). Segundo Metcalfe \& Chalk (1983), os corpos silicosos caracterizam espécies, gêneros e famílias de Liliopsidas, devido a presença e 
forma destas incrustações minerais serem determinadas geneticamente e pouco influenciadas por fatores ambientais (Moller \& Rassmussen 1984).

Os estômatos em secção transversal estão em nível subepidérmico e, raramente, ao mesmo nível das demais células epidérmicas. Possuem células subsidiárias arqueiformes e células-guarda de lume estrito e triangular. Nestes apêndices, a cutícula projeta-se pelas margens externas das paredes anticlinais das célulasguarda e origina uma saliência cuticular inferiormente
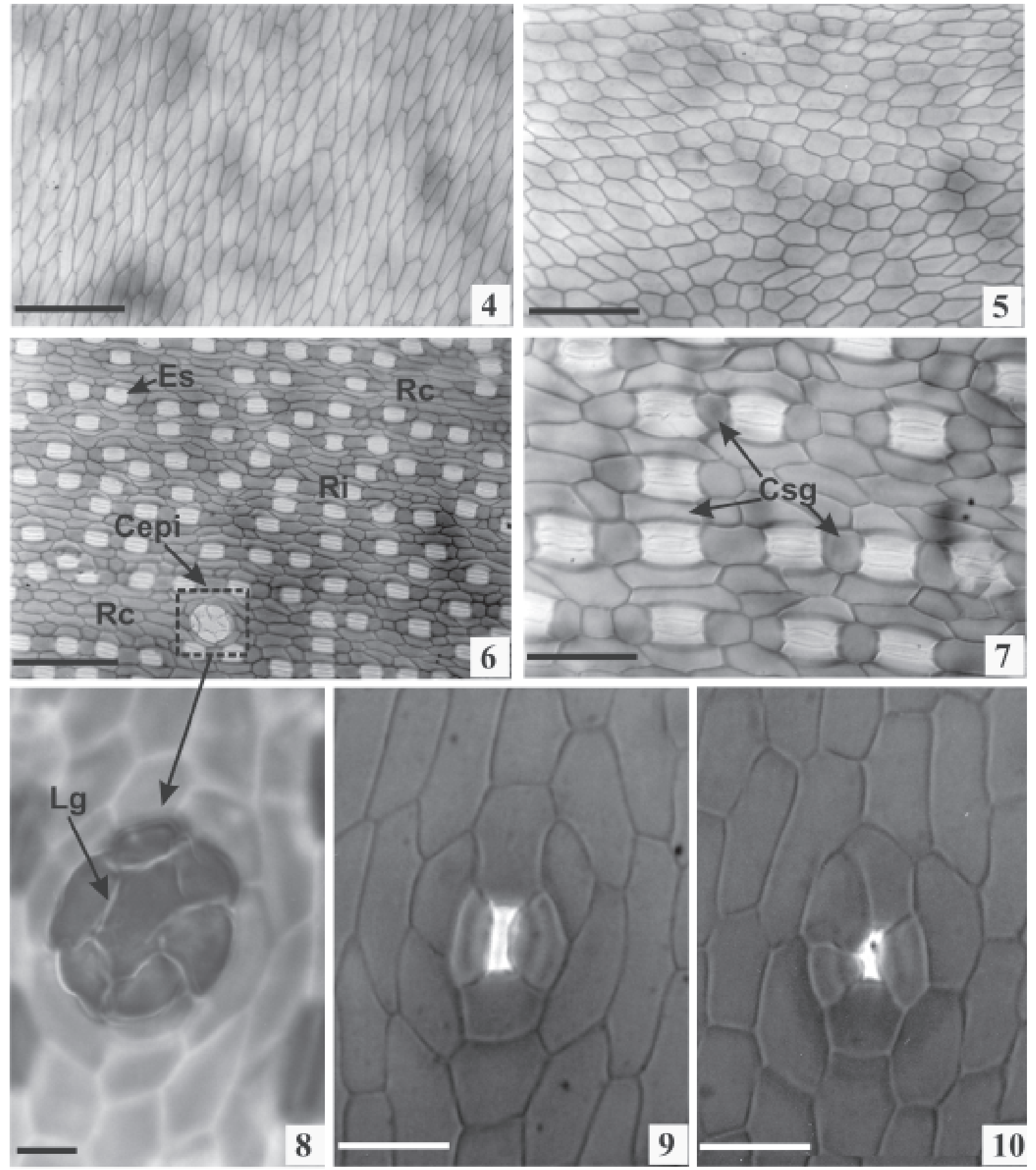

Figuras 4-10. Vista frontal da epiderme das pinas de Oenocarpus Mart. 4-8. O. bacaba Mart. 4-5. Vista geral da epiderme adaxial. 6. Vista geral da epiderme abaxial. 7. Detalhe da epiderme abaxial. 8. Detalhe evidenciando lignificação das paredes das células que circundam a região basal dos tricomas. 9-10. O. minor Mart., epiderme adaxial. 9. Detalhe do estômato tetracítico. 10. Detalhe do estômato ciclocítico. Célula epidérmica imbricada (Cepi); Célula subsidiária geminada (Csg); Estômato (Es); Lignificação (Lg); Região costal (Rc); Região intercostal (Ri). Barras: $4-5=100 \mu \mathrm{m} ; 6=140 \mu \mathrm{m} ; 7=60 \mu \mathrm{m} ; 8=20 \mu \mathrm{m} ; 9-10=60 \mu \mathrm{m}$. 
ao poro estomático, denominada por Metcalfe \& Chalk (1979) e Fahn (1990) de margem cuticular, a qual delimita uma cavidade interna ou dorsal às proximidades da câmara subestomática (Fig. 18-19).

A morfologia e margem cuticular das células-guarda fornecem um importante diagnóstico a nível genérico e específico (Solereder 1908) conforme constatado em publicações de Tomlinson $(1961 ; 1969)$ para as Arecaceae e Commelinales-Zingiberales respectivamente, de Carr \& Carr (1979) a Eucalyptus L'Hér (Myrtaceae) e de Ramassamy \& Kannabiran (1996) a membros de Myrtales.

As bases dos tricomas em secção transversal mostram-se constituídas por quatro a sete células de aspecto elipsoidal, lignificadas e em disposição irregular, situadas internamente no mesofilo e associadas ou não a grupos de braquiesclereídes (Fig. 20-21). Os tricomas em palmeiras apresentam sistema basal multicelular persistente, com células freqüentemente esclerenquificadas ou cutinizadas e afundadas no mesofilo, sendo úteis para fins de diagnóstico taxonômico (Tomlinson 1990).
O mesofilo dos taxa estudados é dorsiventral. O parênquima paliçádico possui de uma a três camadas de células colunares com paredes retas e alongadas no eixo longitudinal. O parênquima lacunoso é formado por células poligonais irregulares com espaços intercelulares reduzidos, exceto nas regiões subjacentes às células estomáticas onde as lacunas delimitam câmaras subestomáticas (Fig. 15, 19).

Cutler (1978) cita que o mesofilo, independente da diferenciação, pode ser utilizado como um critério a mais na identificação de espécies, pois as variações ambientais não alteram os arranjos celulares por estarem rigidamente controlados pelo genoma. Sabe-se, entretanto, que a quantidade de tecido fundamental do mesofilo, a altura do parênquima paliçádico e a compactação do lacunoso não são úteis para fins de diagnóstico, uma vez que sofrem influenciais de fatores como intensidade luminosa, disponibilidade de água do solo, umidade atmosférica e posição da folha na planta segundo Esau (1974) e Raven et al. (2001).
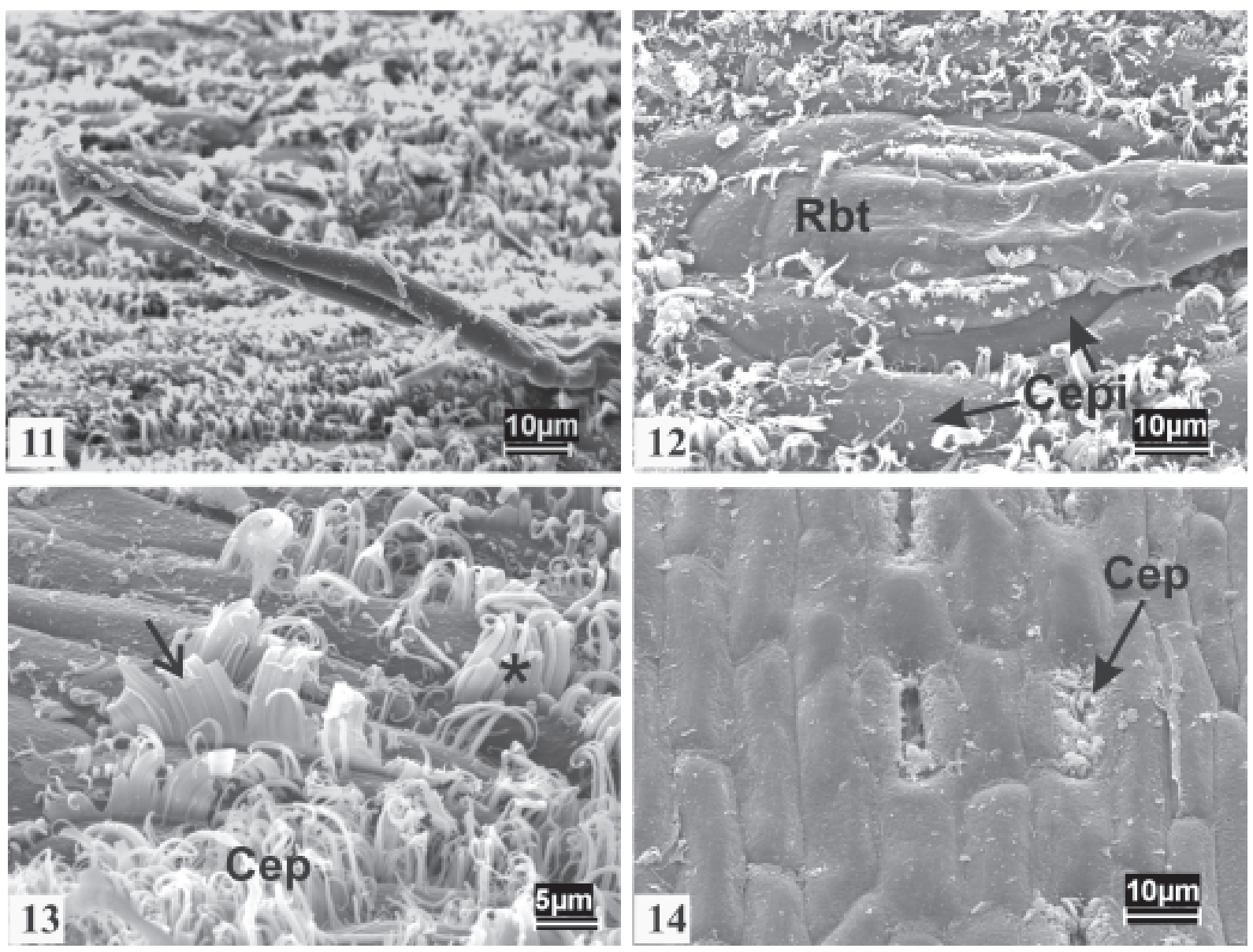

Figuras 11-14. Eletromicrografias dos apêndices epidérmicos das pinas de Oenocarpus Mart. 11-12. O. distichus Mart., face inferior. 11. Tricoma tector. 12. Detalhe das células que circundam a região basal dos tricomas. 13-14. O. mapora H. Karst., face superior. 13. Cera epicuticular. 14. Ostíolo estomático obstruído por cera epicuticular. O asterístico indica cera epicuticular em grupos filamentosos e a seta em placas retangulares. Cera epicuticular (Cep); Célula epidérmica imbricada (Cepi); Região basal do tricoma (Rbt). 
1004 Silva \& Potiguara: Aplicações taxonômicas da anatomia foliar de espécies amazônicas de Oenocarpus Mart. ...
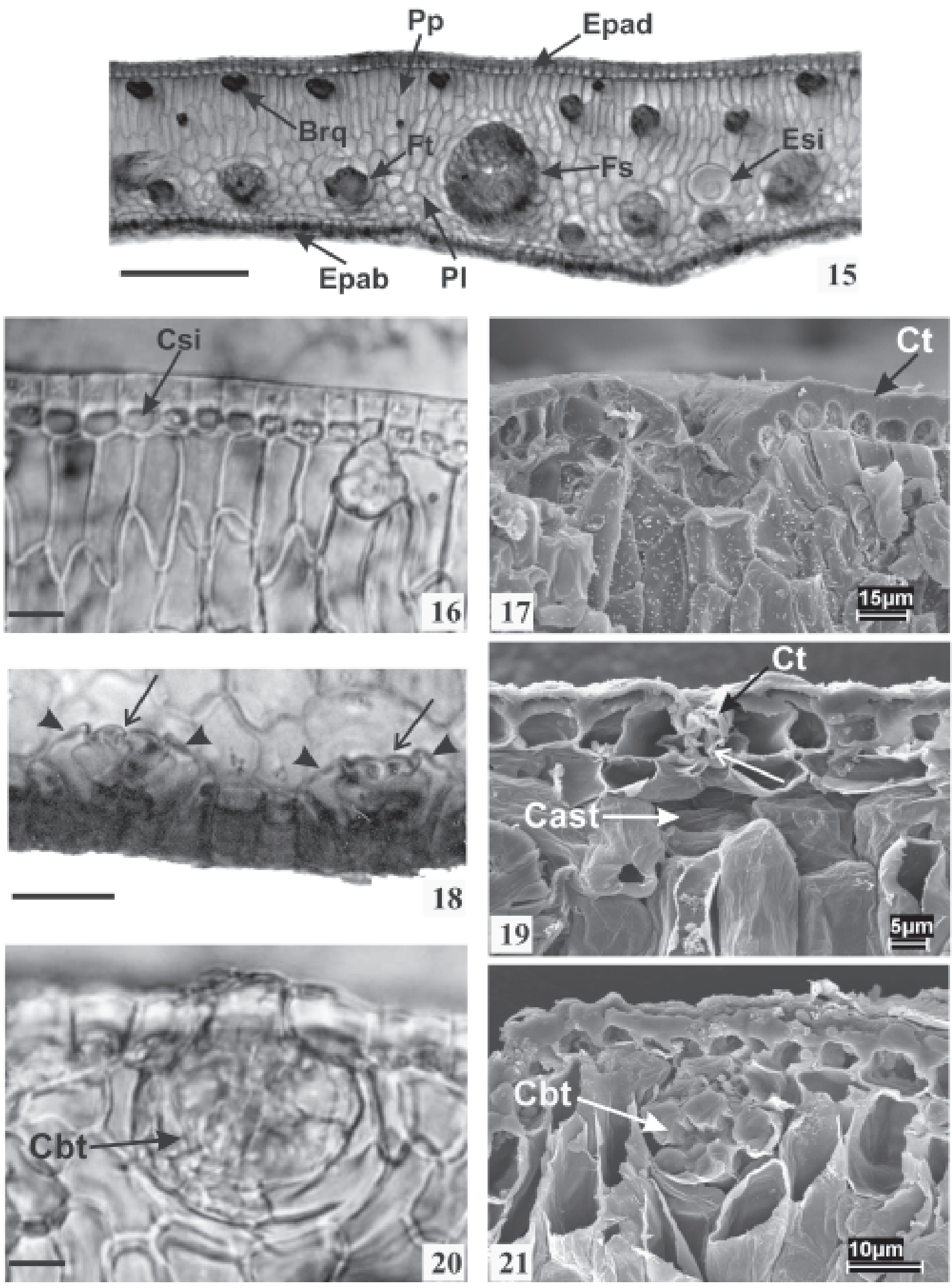

Figuras 15-21. Secções transversais das pinas de Oenocarpus Mart. 15-17. O. bacaba Mart. 15. Vista geral do mesofilo. 16. Epiderme adaxial detalhando corpos silicosos elípticos. 17. Eletromicrografia da epiderme adaxial com invaginação. 18-19. O. minor Mart. 18. Epiderme abaxial mostrando estômatos sub-epidérmicos. 19: Eletromicrografia da epiderme adaxial detalhando estômato sub-epidérmico. 20-21. O. distichus Mart. 20. Detalhe da base do tricoma tector. 21. Eletromicrografia da base do tricoma tector. As setas indicam projeção cuticular e as pontas de seta células subsidiárias. Braquiesclereíde (Brq); Células basais do tricoma (Cbt); Corpo silicoso (Csi); Câmara sub-estomática (Cst); Cutícula (Ct); Epiderme abaxial (Epab); Epiderme adaxial (Epad); Estrutura secretora interna de mucilagem (Esi); Floema (Fl); Feixe secundário (Fs); Feixe terciário (Ft); Parênquima lacunoso (Pl); Parênquima paliçádico (Pp). Barras: $15=200 \mu \mathrm{m} ; 16=20 \mu \mathrm{m} ; 18=60 \mu \mathrm{m} ; 20=20 \mu \mathrm{m}$. 
Grupos de braquiesclereídes encontram-se dispersos no clorênquima, alguns tangenciando as epidermes e associados a stegmatas com corpos silicosos esféricos (Fig. 15, 22). A distribuição dos esclereídeos é de interesse especial quanto ao problema de diferenciação nas plantas (Esau 1974). Trabalhos de Foster (1946), Tomlinson (1959) e Rao \& Dakshni (1963) demonstram a importância taxonômica do padrão de distribuição e morfologia dos esclereídeos foliares como um caracter genérico, assim como observado nas espécies de Oenocarpus Mart. analisadas.

Feixes vasculares colaterais (secundários e terciários) localizam-se principalmente no parênquima lacunoso embora os de dimensões maiores adentrem o paliçádico. Possuem floema indiviso voltado à face abaxial e xilema à adaxial (Fig. 15). Os terciários (de menor porte) possuem meta e protoxilema não distinguíveis, encontram-se envolvidos completa ou parcialmente por bainha parenquimática e apresentam uma pequena concentração de esclerênquima associado a stegmatas com corpos silicosos esféricos ao nível do floema (Fig. 22). Os secundários (de médio porte) com base no número de vasos metaxilemáticos dividem-se em quatro tipos: I, II, III e IV apresentando, respectivamente, um, dois, três e quatro vasos de metaxilema e protoxilema indistinguível. Estes feixes estão circundados por bainha mista, isto é, esclerenquimática (fibras e braquiesclereídes) nos pólos e parenquimática nas laterais, verificando-se uma bainha parenquimática externa de forma parcial (Fig. 23-26).

Os tipos I (Fig. 23), II (Fig. 24) e IV (Fig. 26) ocorrem em O. distichus Mart., O. mapora H. Karst. e O. bacaba Mart. respectivamente. O tipo III (Fig. 25) é comum para todas as espécies. Cutler (1978) assinala que os padrões de arranjo do tecido vascular da lâmina foliar estão sob forte controle genético e por isso sofrem pouca variação ambiental, exceto quanto ao seu número na folha. Sendo assim, a delimitação em tipos proposta aos feixes vasculares acima representa uma relevante adição ao diagnóstico diferencial dos quatro taxa de Oenocarpus Mart., excluindo-se o tipo III por ser comum aos mesmos.

Estruturas secretoras internas ocorrem entre os parênquimas paliçádico e lacunoso (Fig. 15). Em secção transversal, apresentam-se isodiamétricas e delimitadas por epitélio de células semicirculares com paredes delicadas (Fig. 27). Em secção longitudinal, assumem aspecto alongado, com células epiteliais projetando-se parcialmente para o interior do lume da estrutura (Fig. 28). Algumas sem conteúdo aparente e outras com conteúdo mucilaginoso denso.

Tomlinson (1990) cita que as cavidades secretoras de mucilagem em palmeiras consistem de um revestimento interno de células epiteliais com paredes delgadas e bastante indiferenciadas, aparentando terem se originado esquizolisigenamente. Afora as implicações ontogênicas, os espaços visualizados nas pinas de Oenocarpus Mart. são aqui considerados esquizógenos devido às evidências estruturais.

A nervura central em secção transversal apresentase mais proeminente adaxialmente, situando-se na região mediana do limbo das pinas (Fig. 29-32). O preenchimento parenquimático consiste de células heterodimensionais com formas geralmente esféricas, ocorrendo grupos de braquiesclereídes associados ou não a stegmatas com corpos silicosos esféricos, situados principalmente nas adjacências da epiderme. Os esclereídeos distribuem-se por toda a extensão da nervura em O. minor Mart. (Fig. 31) e nas três outras espécies situam-se, principalmente, no parênquima voltado à face adaxial (Fig. 29-30, 32).

A maior parte desta região está ocupada por tecido esclerenquimático (fibras e braquiesclereídes) compacto, contínuo em O. minor Mart. (Fig. 31) e interrompido por parênquima ao nível mediano da nervura nas demais espécies (Fig. 29-30, 32). Feixes vasculares colaterais com floema indiviso e bipartido por um tabique esclerenquimático horizontal ocorrem dispersos no esclerênquima. Observou-se, ainda, massa isolada de tecido floemático em O. bacaba Mart. (Fig. 29) e O. minor Mart. (Fig. 31).

A forma da nervura central varia, sendo elíptica em O. bacaba Mart. (Fig. 29) e O. mapora H. Karst. (Fig. 30); côncava na face abaxial e retilínea com arestas arredondadas na face adaxial em O. minor Mart. (Fig. 31) e irregular com ligeira sinuosidade em $O$. distichus Mart. (Fig. 32).

A margem em secção transversal mostra-se quadrangular em $O$. bacaba Mart. (Fig. 33); retangular em $O$. distichus Mart. (Fig. 34) e deltóide em O. minor Mart. (Fig. 35). Em O. mapora H. Karst., a margem não possui forma geométrica definida, sendo convexa na face adaxial e retilínea nas faces abaxial e lateral (Fig. 36).

Características anatômicas da nervura central e margem foliar representam um caractere útil à identificação e separação de taxa pertencentes ao mesmo gênero consoante demonstrado por outros autores (Tomlinson 1960; Glassman 1972; D’Arcy \& Keating 1979; Sajo et al. 1995; Bieras \& Sajo 2004; Scatena et al. 2004) ratificando a relevância destas estruturas ao diagnóstico e taxonomia das espécies de Oenocarpus Mart. analisadas.

Secções transversais do limbo das pinas revelaram que no limite do mesofilo com a nervura central, subjacentes à epiderme abaxial, ocorrem células 
1006 Silva \& Potiguara: Aplicações taxonômicas da anatomia foliar de espécies amazônicas de Oenocarpus Mart. ...
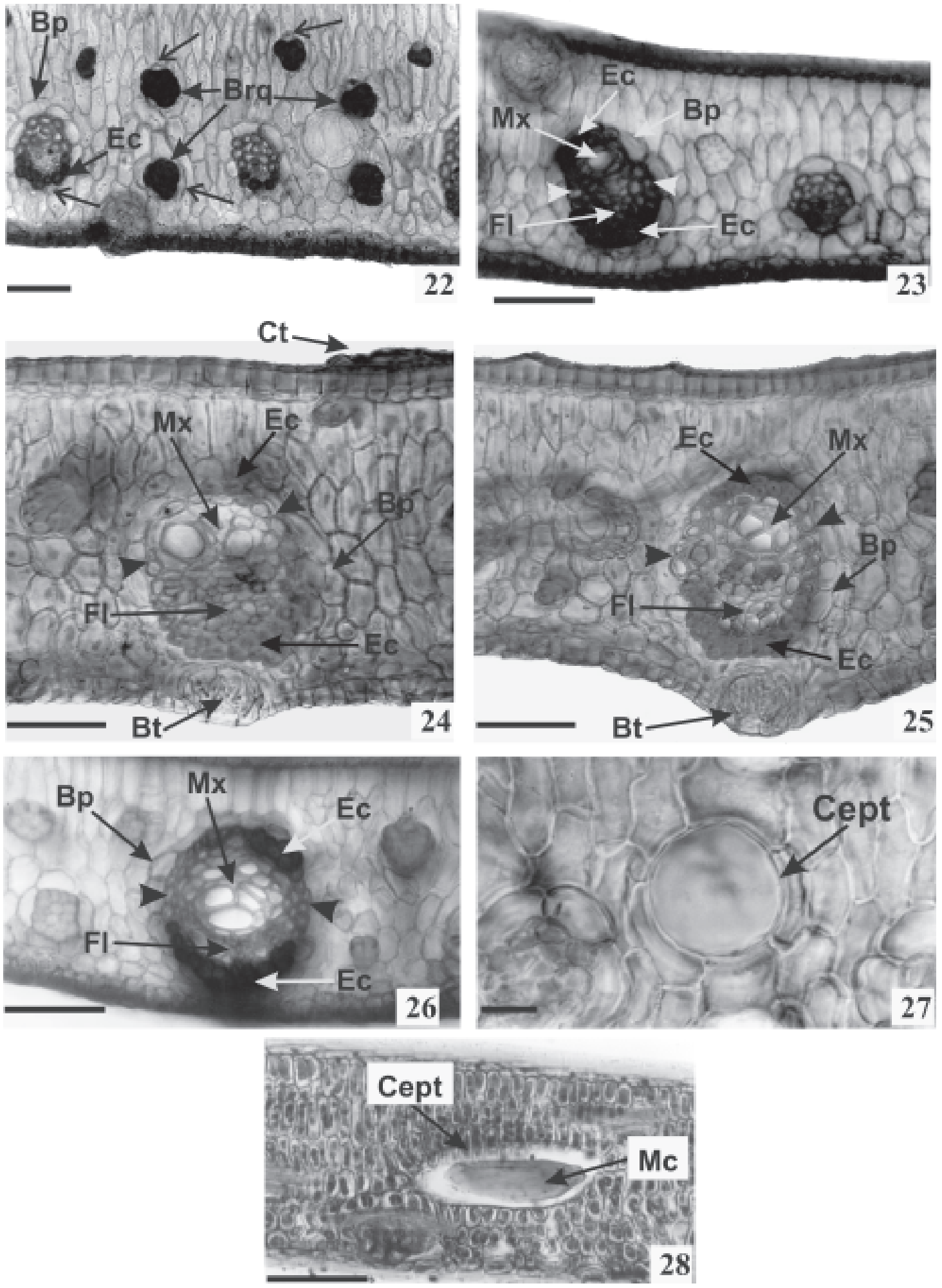

Figuras 22-28. Secções transversais das pinas de Oenocarpus Mart. 22. Mesofilo de $O$. bacaba Mart. mostrando braquiesclereídes e feixes vasculares terciários. 23. Mesofilo de $O$. distichus Mart. detalhando feixe vascular secundário tipo I. 24. Mesofilo de $O$. mapora H. Karst. detalhando feixe vascular secundário Tipo II. 25. Mesofilo de $O$. minor Mart. detalhando feixe vascular secundário Tipo III. 26. Mesofilo de O. bacaba Mart. detalhando feixe vascular secundário Tipo IV. 27-28: Mesofilo de O. minor Mart. 27. Estrutura secretora interna de mucilagem em secção transversal; 28: Estrutura secretora interna de mucilagem em secção longitudinal. As setas indicam stegmatas e as pontas de seta parênquima. Bainha parenquimática (Bp); Braquiesclereíde (Brq); Base do tricoma (Bt); Célula epitelial (Cept); Cutícula (Ct); Esclerênquima (Ec); Floema (Fl); Metaxilema (Mx), Mucilagem (Mc). Barras: $22=50 \mu \mathrm{m} ; 23=100 \mu \mathrm{m} ; 24-25=60 \mu \mathrm{m} ; 26=100 \mu \mathrm{m} ; 27=20 \mu \mathrm{m}$; $28=100 \mu \mathrm{m}$. 
parenquimáticas em paliçada alongadas no eixo longitudinal, de paredes espessadas e em disposição oblíqua à diagonal, denominadas de tecido de expansão por Tomlinson (1990). Este tecido é pluriestratificado com três camadas celulares em $O$. minor Mart. e uniestratificado nas três outras espécies (Fig. 37-38).

Tomlinson (1961) considera que o tecido de expansão está relacionado com mecanismos de flexibilidade das pinas, ou seja, com movimentos de dobramento e desdobramento que resultam de mudanças
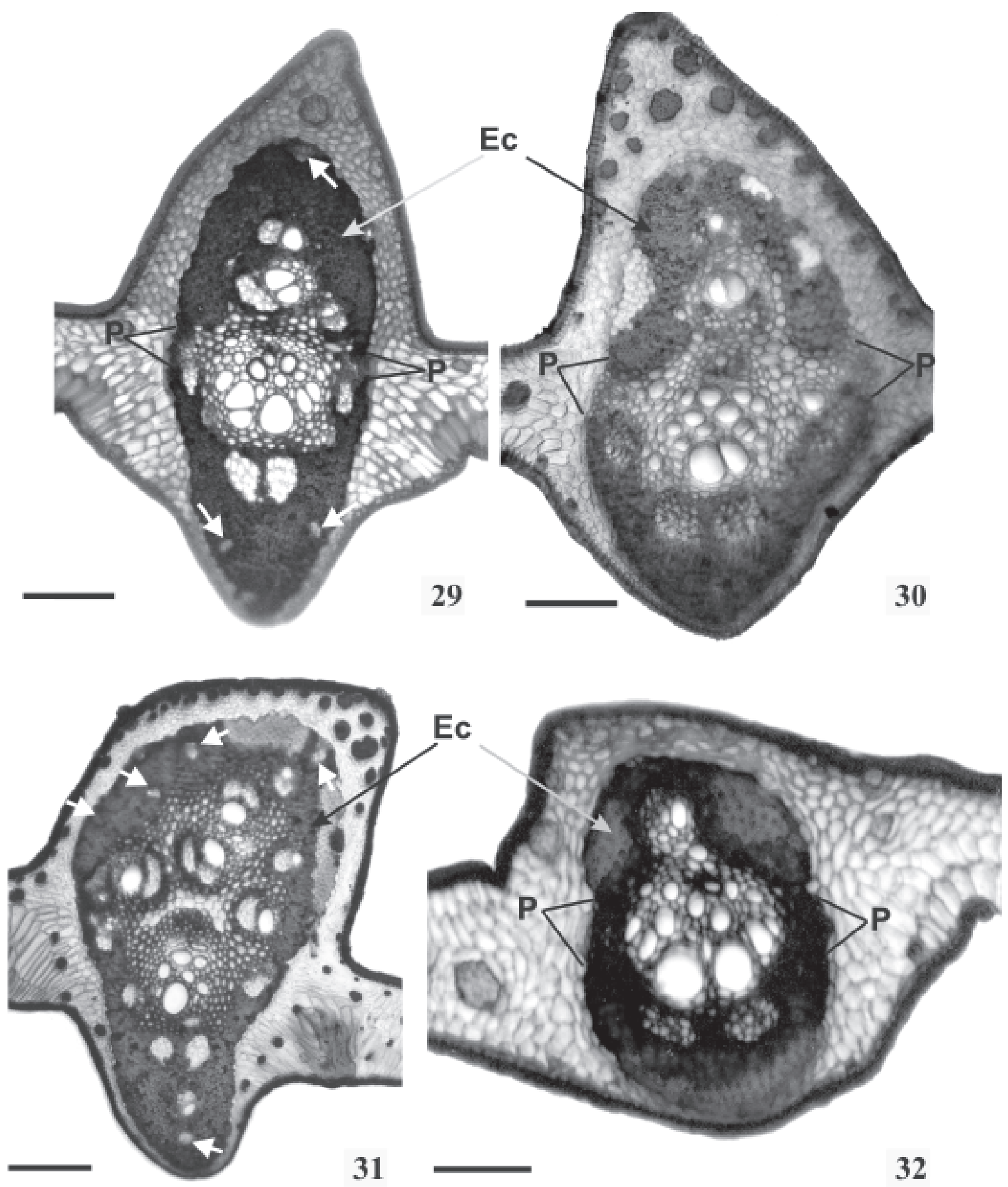

Figuras 29-32. Secções transversais da nervura central de Oenocarpus Mart. 29. O. bacaba Mart. 30. O. mapora H. Karst. 31. O. minor Mart. 32. . distichus Mart. As setas indicam massas isoladas de tecido floemático. Esclerênquima (Ec); Parênquima (P). Barras: 29-31 = 140 $\mu$ m; $32=200 \mu \mathrm{m}$ 
na pressão de turgor das células, por isso denominados de hidronásticos ou higronásticos (Salisbury \& Ross 1991).

Axis foliar - O parênquima em secção transversal consiste de células heterodimensionais (Fig. 39-49). Células parenquimáticas esféricas ocorrem ao longo desta estrutura em todas as espécies, sendo as únicas observadas na ráquis de O. bacaba Mart. (Fig. 39) e bainha foliar de O. minor Mart. (Fig. 49). Nas regiões central e mediana, ocorrem também faixas de células
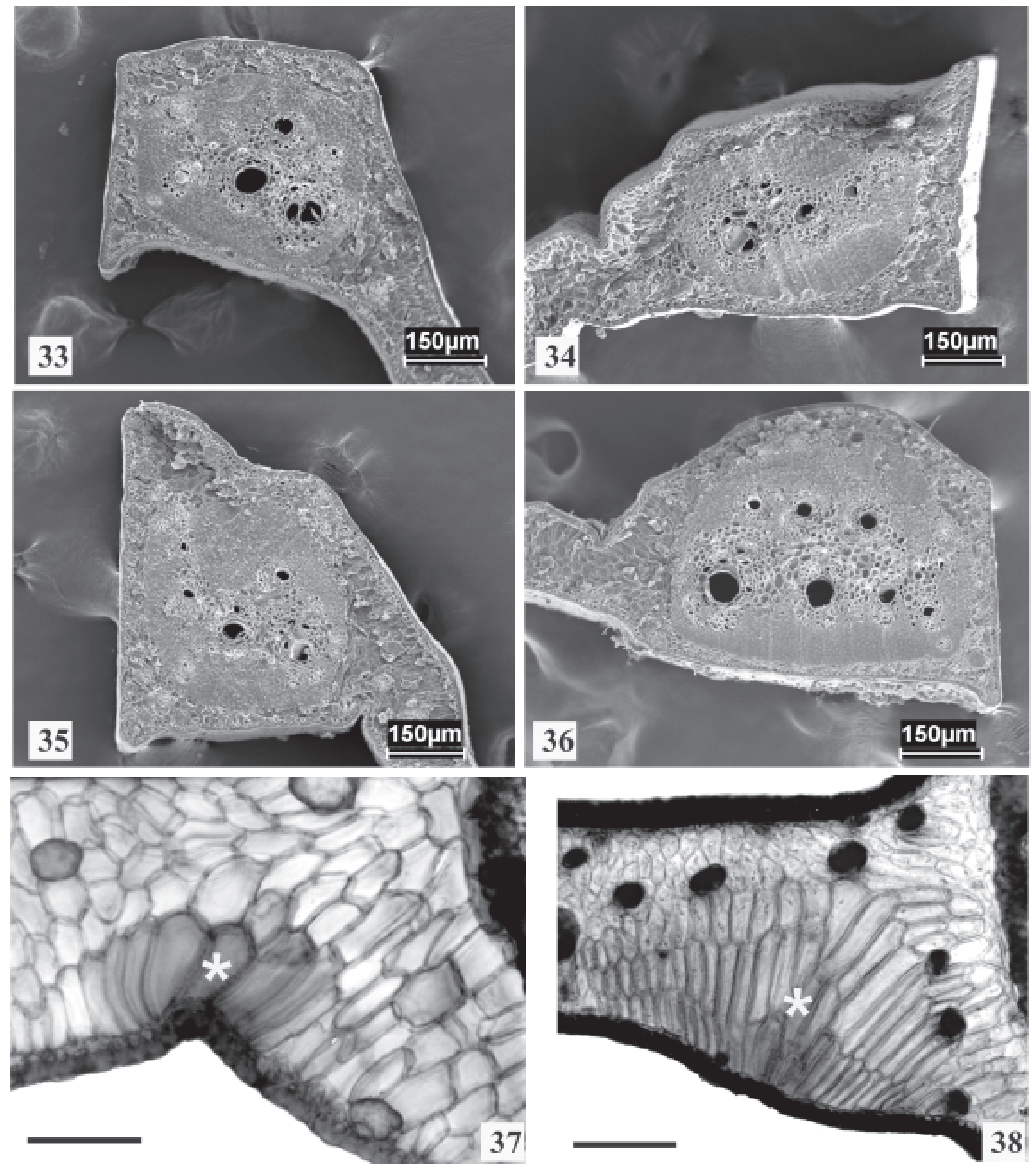

Figuras 33-38. Secções transversais das pinas de Oenocarpus Mart. 33-36. Eletromicrografias da margem. 33. O. bacaba Mart. 34. O. distichus Mart. 35. O. minor Mart. 36. O. mapora H. Karst. 37. O. bacaba Mart., detalhando tecido de expansão uniestratificado. 38. O. minor Mart., detalhando tecido de expansão pluriestratificado. Os asteriscos indicam o tecido de expansão. Barras: 37-38 = $100 \mu \mathrm{m}$. 
parenquimáticas com forma e organização características para cada taxa estudado.

Ráquis - Apresenta faixas de células elípticas dispostas de maneira isolada em O. distichus Mart. (Fig. 40), contínua em O. mapora H. Karst. (Fig. 41) e contínua confluente em O. minor Mart. (Fig. 42).

Pecíolo - A histologia parenquimática de $O$. distichus Mart., O. minor Mart. e O. bacaba Mart. (Fig. 43) assemelha-se ao da ráquis de $O$. mapora $\mathrm{H}$. Karst. No pecíolo desta espécie, as faixas são contínuas e formadas
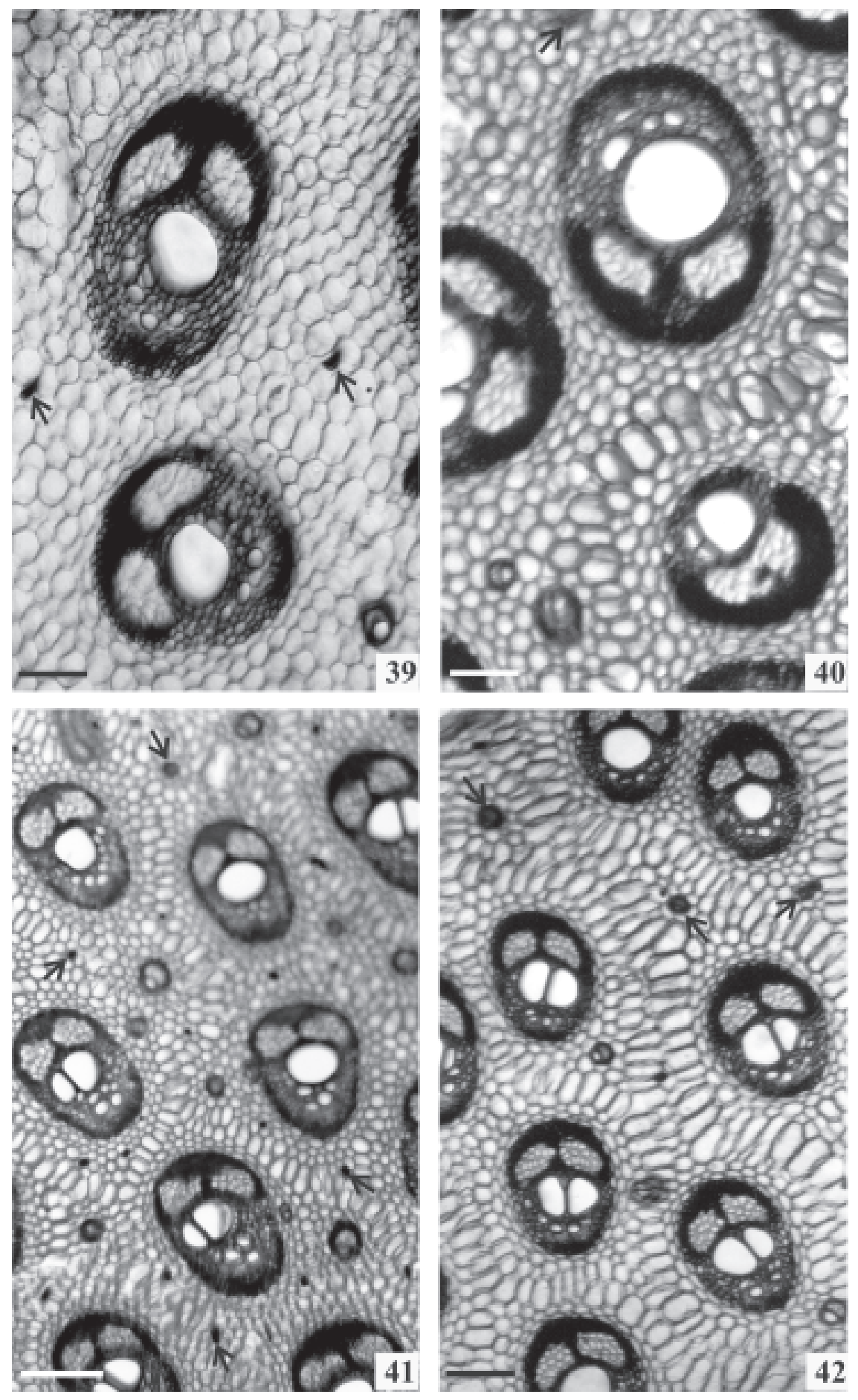

Figuras 39-42. Secções transversais da região central da ráquis de Oenocarpus Mart., evidenciando o tecido parenquimático. 39. O. bacaba Mart. 40. O. distichus Mart. 41. O. mapora H. Karst. 42. O. minor Mart. As setas indicam fibras isoladas e em feixes. Barras: $39-40=200 \mu \mathrm{m}$; $41=350 \mu \mathrm{m} ; 42=200 \mu \mathrm{m}$. 
por células colunares com paredes aparentemente sofrendo processo esquizógeno, levando a formação de lacunas aeríferas (Fig. 44-45).

Bainha foliar - Possui faixas de células retangulares justapostas em $O$. bacaba Mart. (Fig. 46); fusiformes em O.distichus Mart. (Fig.47); elipsóides e retangulares em O. mapora H. Karst. (Fig. 48). As faixas celulares dispõem-se de maneira longitudinal, contínua e isolada respectivamente. Em O. mapora $\mathrm{H}$. Karst., as paredes das células elipsóides e retangulares assemelham-se as das colunares do pecíolo, mas, não ocorre formação de lacunas aeríferas e sim uma tendência em formá-las.

Estudos sobre o axix foliar de Arecaceae têm se limitado às funções mecânica e hidráulica (Tomlinson

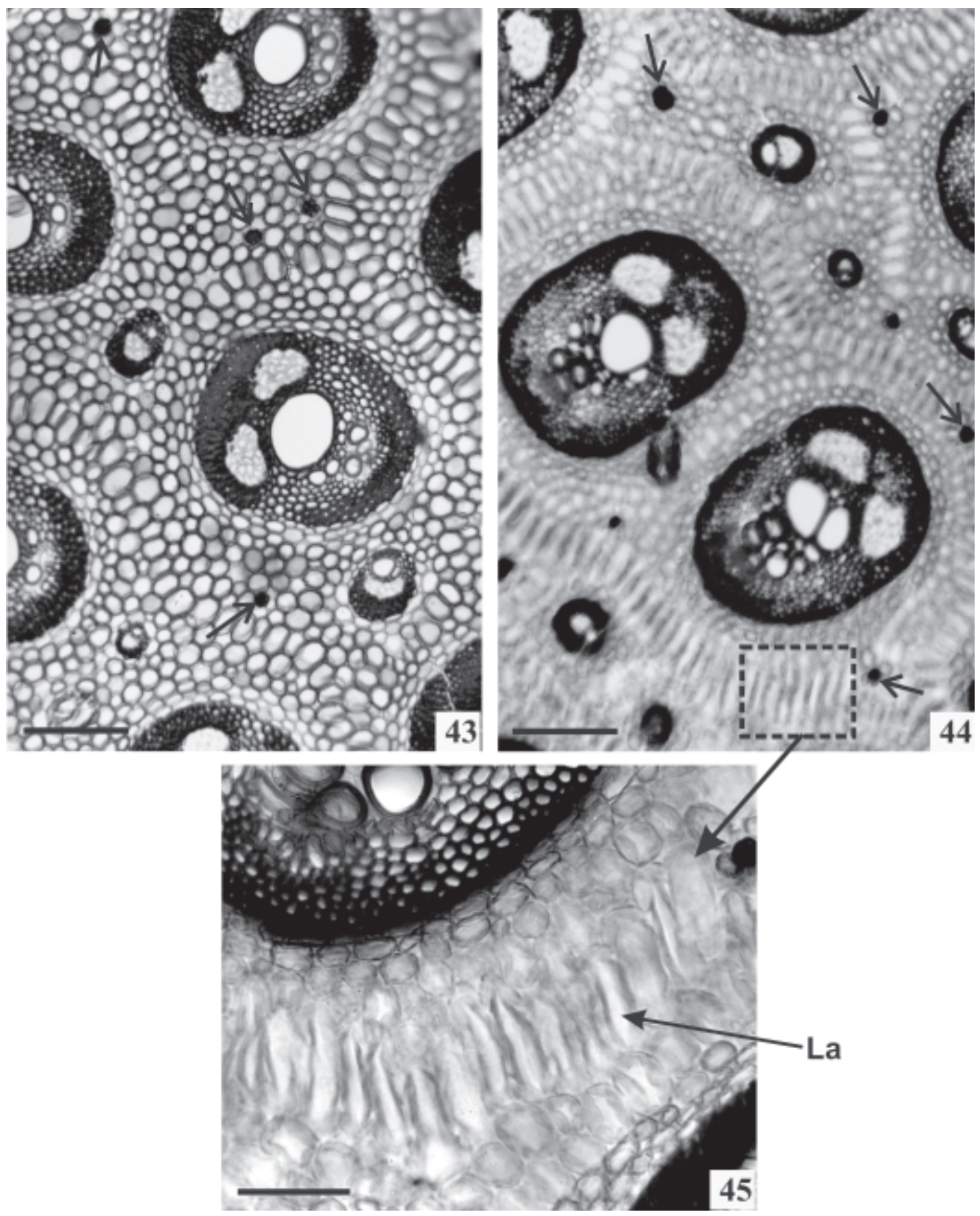

Figuras 43-45. Secções transversais da região central do pecíolo de Oenocarpus Mart., evidenciando o tecido parenquimático. 43. O. bacaba Mart. 44-45. O. mapora H. Karst. 45. Detalhe de 44 mostrando células de aspecto colunar e lacunas aeríferas. As setas indicam feixes de fibra. Lacuna aerífera (La). Barras: 43-44 = $220 \mu \mathrm{m} ; 45=140 \mu \mathrm{m}$. 
1964; Dassanayake \& Sivakadachchan 1972; Pyykkö 1985). Quando se referem à disposição dos tecidos para fins evolutivos (Cheadle 1942; 1944) ou sistemáticos (Parthasarathy 1968; Klotz 1978) focam apenas xilema e floema. Entretanto, a forma e organização das células parenquimáticas revelam-se úteis na separação de espécies (Weiner \& Liese 1993) como verificado nos taxa de Oenocarpus Mart. estudados.

Feixes vasculares colaterais, fibras isoladas e em feixes ocorrem dispersos no parênquima do axis foliar das espécies. Na bainha foliar, os feixes fibrosos estão envoltos por bainha contínua de stegmatas com corpos silicosos esféricos (Fig. 50). Estes idioblastos silicosos dispõem-se em fileiras longitudinais, adjacentes e
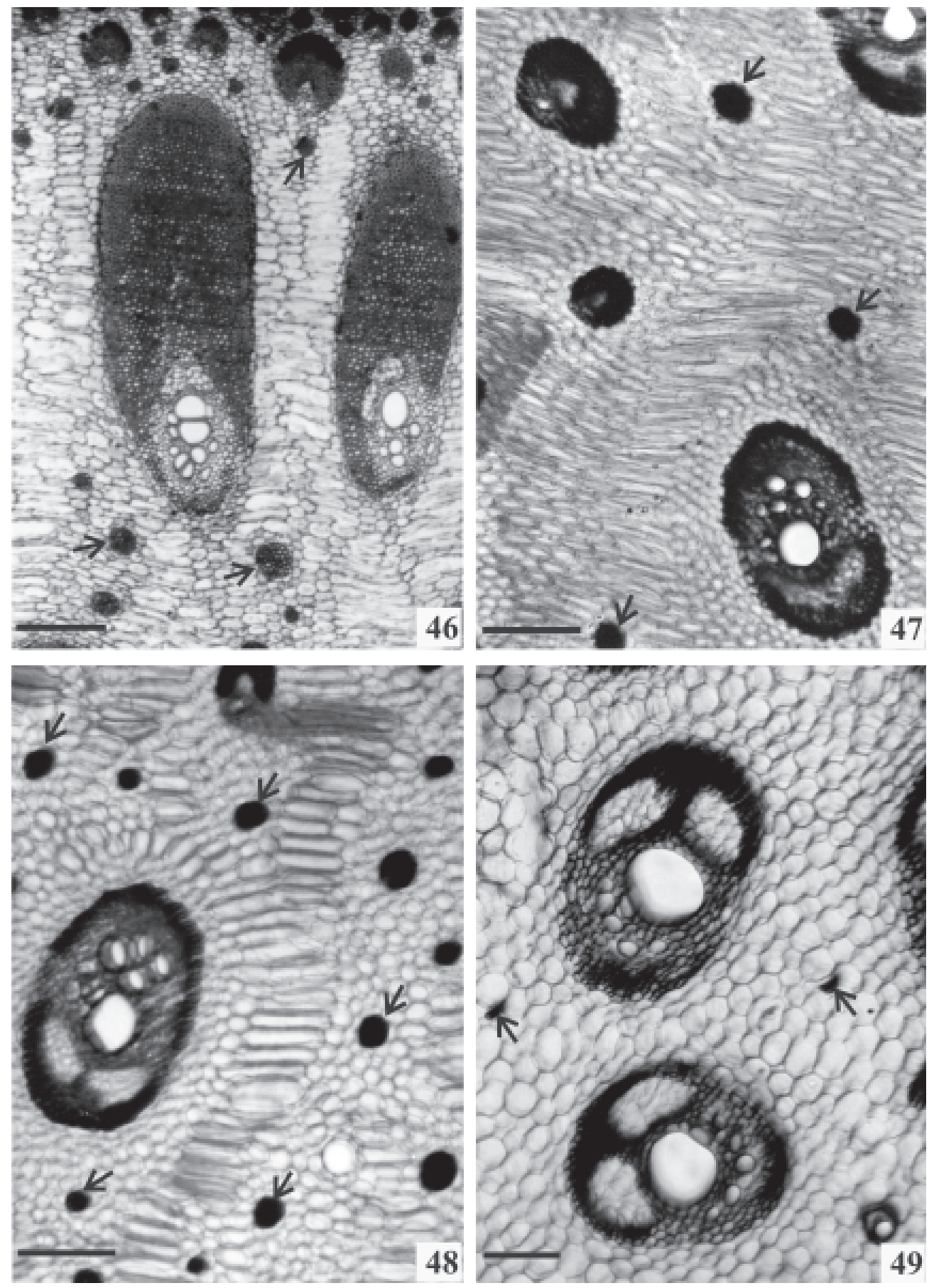

Figuras 46-49. Secções transversais da região central da bainha foliar de Oenocarpus Mart., evidenciando o tecido parenquimático. 46. $O$. bacaba Mart. 47. O. distichus Mart. 48. O. mapora H. Karst. 49. O. minor Mart. As setas indicam fibras isoladas e em feixes envoltos por bainha de stegmatas. Barras: $46=700 \mu \mathrm{m} ; 47-48=220 \mu \mathrm{m} ; 49=200 \mu \mathrm{m}$. 
paralelas aos feixes de fibras, possuem paredes espessadas, forma discóide e uma cavidade ou depressão central na qual se situa o corpo de sílica, de aspecto esférico-globoso e superfície espiculada semelhante a drusas (Fig. 51), apresentando elevada concentração de dióxido de silício $\left(\mathrm{SiO}_{2}\right)$ dectada pela análise em EDS (Fig. 52).

Para as folhas das espécies de Oenocarpus Mart. aqui estudadas, pode-se dizer que alguns caracteres são comuns, enquanto outros ocorrem apenas em determinados taxa. Os caracteres comuns incluem pinas anfiestomáticas com cera epicuticular, cutícula lisa, estômatos tetracíticos e tricomas tectores; mesofilo dorsiventral com braquiesclereídes em grupos, estruturas secretoras de mucilagem e com feixe vascular colateral do tipo III. Entre os de ocorrência restrita cita-se: estômatos ciclocíticos; características da nervura central como a forma, padrão de distribuição do esclerênquima e presença ou ausência de massas isoladas de tecido floemático; forma da margem; estratificação do tecido de expansão; forma e organização do parênquima nas regiões central e mediana do axis foliar e especificidade de alguns tipos de feixe vasculares do mesofilo.

A ocorrência ou não dos diferentes caracteres observados permitiu elaborar a seguinte chave de identificação anatômica para as espécies amazônicas de Oenocarpus Mart., demonstrando que há entre estas diferenças estruturais significativas a nível qualitativo.
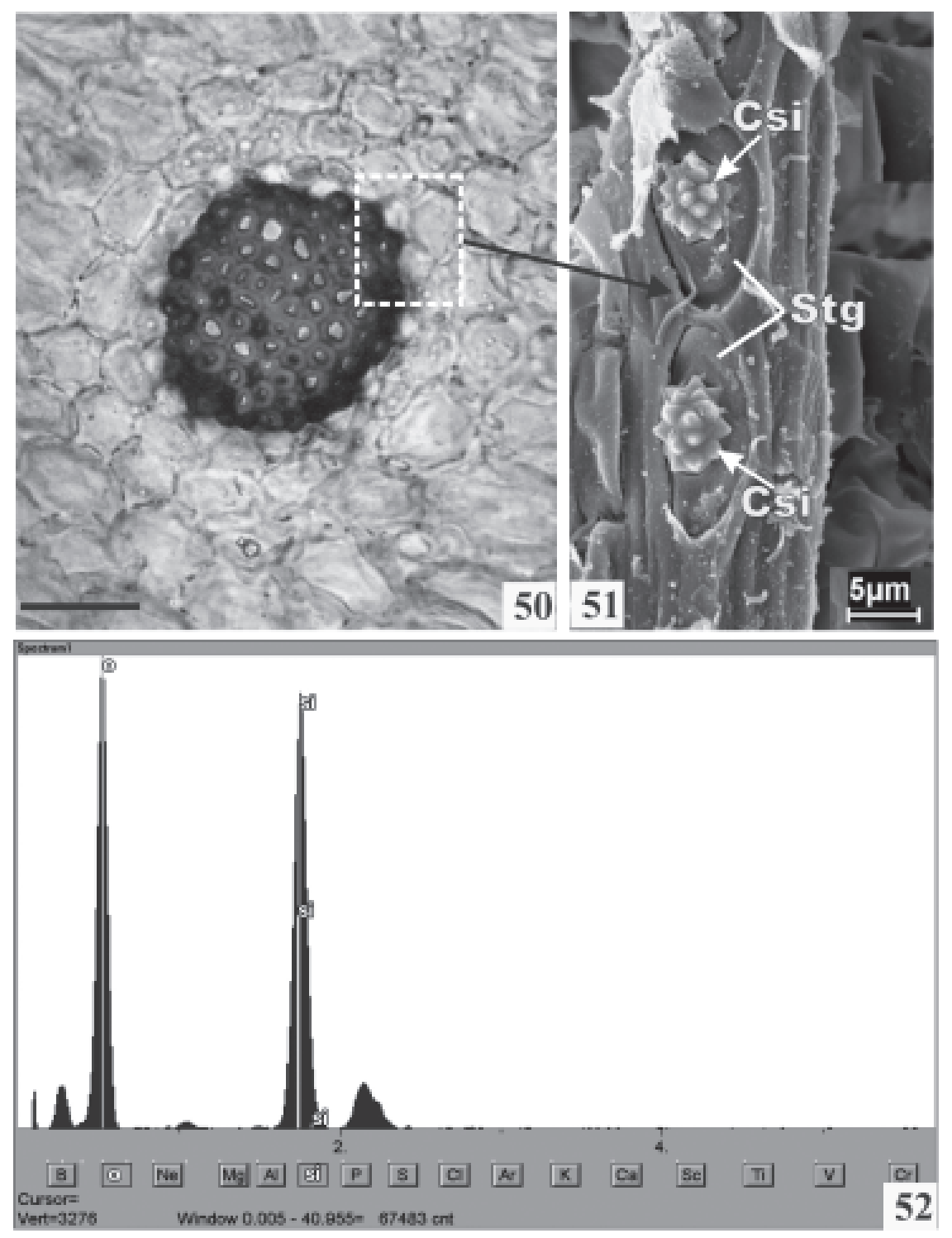

Figuras 50-51. Secções transversais da bainha foliar de Oenocarpus distichus Mart. 50. Feixe fibroso envolto por bainha contínua de stegmatas. 51. Eletromicrografia detalhando uma região de 50. 52. Espectro da análise em EDS realizada nos corpos silicosos de 51. Corpo silicoso (Csi); Stegmatas (Stg). Barra: $50=100 \mu \mathrm{m}$. 
Chave de identificação anatômica para as espécies estudadas de Oenocarpus Mart.

1. Nervura central apresentando tecido esclerenquimático contínuo, tecido de expansão pluriestratificado, margem de forma deltóide, ráquis constituída por células parenquimáticas de aspecto elíptico dispostas em faixas contínuas confluentes

O. minor

1. Nervura central apresentando tecido esclerenquimático descontínuo, tecido de expansão uniestratificado, margem de outras formas, ráquis constituída por células parenquimáticas de outros aspecto e organização

2. Epiderme apresentando apenas estômatos tetracíticos, margem de forma geométrica definida, pecíolo constituído por células parenquimáticas de aspecto elíptico

3. Feixe vascular colateral do mesofilo tipo IV, nervura central de forma elíptica e com massas isoladas de tecido floemático, margem de forma quadrangular, bainha foliar constituída por células parenquimáticas de aspecto retangular dispostas em faixas longitudinais

3. Feixe vascular colateral do mesofilo tipo I, nervura central de forma irregular e sem massas isoladas de tecido floemático, margem de forma retangular, bainha foliar constituída por células parenquimáticas de aspecto fusiforme dispostas em faixas contínuas..... O. distichus

2. Epiderme apresentando estômatos tetracíticos e ciclocíticos, margem de forma geométrica indefinida, pecíolo constituído por células parenquimáticas de aspecto colunar.

\section{Agradecimentos}

Ao Conselho Nacional de Desenvolvimento Científico e Tecnológico (CNPq), pela concessão da bolsa de Mestrado; à Dra. Raimunda Conceição de Vilhena Potiguara, pela orientação e ensinamentos sobre as palmeiras; ao ilustrador científico Carlos Alvarez, pelos desenhos em planta baixa.

\section{Referências bibliográficas}

Balick, M. 1984. Ethnobotany of palms in the neotropics. Advances in Economic Botany 1: 9-23.

Balick, M. 1986. Systematics and economic botany of the Oenocarpus-Jessenia (Palmae) complex. Advances in Economic Botany 3: 1-140.

Bieras, A.C. \& Sajo, M.G. 2004. Anatomia foliar de Erythroxylum P. Browne (Erythroxylaceae) do cerrado do estado de São Paulo, Brasil. Acta Botanica Brasilica 18: 601-612.

Carlquist, S. 1982. The use of ethylenediamine in softening hard plant structures for paraffin sectioning. Stain technology 57: 311-317.

Carr, S.G. \& Carr, D.J. 1979. An unusual feature of stomatal microanatomy in certain taxonomically related Eucalyptus spp. Annals of Botany 44: 239-243.

Cheadle, V.I. 1942. The occurrence and types of vessels in the various organs of the plant in the Monocotyledoneae. American Journal of Botany 29: 441-450.

Cheadle, V.I. 1944. Specialization of vessels within the xylem of each organ in the Monocotyledoneae. American Journal of Botany 31: 81-92.

Cronquist, A. 1981. An integrated system of the classification of flowering plants. New York, Columbia University Press.

Cutler, D.F. 1978. Applied plant anatomy. London, Longman.

D'Arcy, W.G. \& Keating, R.C. 1979. Anatomical support for the taxonomy of Calophyllum L. (Clusiaceae) in Panama. Annals of Missouri Botanical Garden 66: 557-571.

Dahlgren, R.M.T. \& Clifford, H.T. 1982. The monocotyledons: a comparative study. London, Academic Press.
Dassanayake, M.D. \& Sivakadachchan, B. 1972. The vascular skeleton of the leaf base of Caryota urens. Phytomorphology 22: 296-304.

Dransfield, J. \& Uhl, N.W. 1986. An outline of the classification of palms. Principes 30: 3-11.

Esau, K. 1974. Anatomia de plantas com sementes. São Paulo, Edgard Blücher.

Fahn, A. 1990. Plant anatomy. $4^{\text {th }}$ ed. New York, Pergamon Press.

Foster, A.S. 1946. Comparative morphology of the foliar sclereids in the genus Mouriria Aubl. Journal of the Arnold Arboretum 27: $253-271$.

Glassman, S.F. 1972. Systematic studies in the leaf anatomy of palm genus Syagrus. American Journal of Botany 59: 775-788.

Henderson, A.; Galeano, G. \& Bernal, R. 1995. Field guide to the Palms of the Americas. New Jersey, Princeton University Press.

Jardim, M.A.G. \& Cunha, A.C.C. 1998. Usos de palmeiras em uma comunidade ribeirinha do estuário amazônico. Boletim do Museu Paraense Emílio Goeldi, série botânica14: 69-67.

Jardim, M.A.G. \& Stewart, P.J. 1994. Aspectos etnobotânicos e ecológicos de palmeiras no município de Novo Airão, Estado do Amazonas, Brasil. Boletim do Museu Paraense Emílio Goeldi, série botânica 10: 69-76.

Jensen, W.A. 1962. Botanical histochemistry: principles and practice. San Francisco, W.H. Freeman.

Johansen, D.A. 1940. Plant microtechnique. New York, MacGrawHill Book Co.

Kahn, F. 1988. Species richness and density of palms in terra firme forest of Amazonia. Biotropica 20: 266-269.

Kahn, F. \& De Granville, J.J. 1992. Palms in forest ecosystems of Amazonia. Ecological Studies 95. Berlin, Springer-Verlag.

Klotz, L.H. 1978. The number of wide vessels in petiolar vascular bundles of palms: an anatomical feature of systematic significance. Principes 22: 64-69.

Kraus, J.E. \& Arduin, M. 1997. Manual básico de métodos em morfologia vegetal. Rio de Janeiro, EDUR.

Metcalfe, C.R. \& Chalk, L. 1979. Anatomy of the dicotyledons. $2^{\text {nd }}$ ed. v. 1. Oxford, Claredon Press.

Metcalfe, C.R. \& Chalk, L. 1983. Anatomy of the dicotyledons Wood structure and conclusion of the general introduction. $2^{\text {nd }}$ ed. v. 2. Oxford, Claredon Press

Miranda, I.P. Avaliação do potencial do uso de algumas palmeiras da Amazônia. Pp. 248. In: Desafios da botânica brasileira no novo milênio: inventário, sistematização e conservação da diversidade vegetal. 2003. Belém, MPEG; UFRA; EMBRAPA, Brasil/Museu Paraense Emílio Goeldi. 
Moller, J.D. \& Rasmussen, F.L.S. 1984. Stegmata in Orchidales: character state distribution and polarity. Botanical Journal the Linnean Society 89: 53-76.

Parthasarathy, M.V. 1968. Observation on metaphloem in vegetative parts of palms. American Journal of Botany 55: 1140-1168.

Pyykkö, M. 1985. Anatomy of the stem and petiole of Raphia hookeri (Palmae). Annales Botanici Fennici 22: 129-138.

Ramassamy, V. \& Kannabiran, B. 1996. Studies on the epidermal and stomatal morphology in transection in some members of Myrtales. Phytomorphology 46: 89-97.

Rao, T.A. \& Dakshni, K.M.M. 1963. Systematics of Memecylon - A preliminary survey based on the sclereids morphology. Indian Academy Science 30: 28-35.

Raven, P.H.; Evert, R.F. \& Eichhorn, S.E. 2001. Biologia vegetal. $6^{a}$ ed. Guanabara, Koogan S.A.P.

Rocha, A.E.S. \& Silva, M.F.F. 2005. Aspectos fitossociológicos, florísticos e etnobotânicos das palmeiras (Arecaceae) de floresta secundária no município de Bragança, PA, Brasil. Acta Botanica Brasilica 19: 657-667.

Sajo, M.G.; Wanderley, M.G.L. \& De Carvalho, L.M. 1995. Caracterização anatômica foliar para 14 espécies de Xyris L. (Xyridaceae) Serra do Cipó, MG, Brasil. Acta Botanica Brasilica 9: 101-114.

Salatino, A. \& Silva, J.B. 1975. Anatomia e óleos essências das folhas de Piper regnellii (Miq.) C.D.C var. regnellii. Boletim de Botânica da Universidade de São Paulo 3: 95-106.
Salisbury, F.B. \& Ross, C.W. 1991. Plant physiology. $4^{\text {th }}$ ed. Belmont, Wadsworth.

Scatena, V.L.; Vich, D.V. \& Parra, L.R. 2004. Anatomia de escapos, folhas e brácteas de Syngonanthus sect. Eulepis (Bong. ex Koern.) Ruhland (Eriocaulaceae). Acta Botanica Brasilica 18: 825-837.

Solereder, H. 1908. Systematic anatomy of the dicotyledons. v.2. Oxford, Clarendon Press.

Souza, V.C. \& Lorenzi, H. 2005. Botânica Sistemática. São Paulo, Instituto Plantarum.

Tomlinson, P.B. 1960. Anatomy of the monocotyledons-I. Gramineae. New York, Oxford University Press.

Tomlinson, P.B. 1961. Anatomy of the monocotyledons-II. Palmae. New York, Oxford University Press.

Tomlinson, P.B. 1964. The vascular skeleton of coconut leaf base. Phytomorphology 14: 218-230.

Tomlinson, P.B. 1969. Anatomy of the monocotyledons-III. Commelinales-Zingiberales. New York, Oxford University Press.

Tomlinson, P.B. 1990. The structural biology of palms. New York, Oxford University Press.

Uhl, N.W. \& Dransfield, J. 1987. Genera Palmarum: a classification of palms based on the work of Harold $E$. Moore Jr. Kansas, Allen Press.

Weiner, G. \& Liese, W. 1993. Generic identification key to rattan palms based on stem anatomy characters. IAWA Journal 14: $55-61$. 